\title{
A rare soft tissue tumor located in the trunk: Ossifying fibromyxoid tumor
}

\author{
Yelda Dere' ${ }^{1}$ Serkan Yașar Çelik¹, Özgür İlhan Çelik , Özcan Dere²
}

\section{ABSTRACT}

Cite this paper as: Dere Y, Çelik SY, Çelik ÖI, Dere

$0 \ddot{0}$ A rare soft tissue tumor located in the trunk: Ossifying fibromyxoid tumor. Turk J Surg 2017; 33: 299-301.

'Department of Pathology, Muğla Sıtkı Koçman University School of Medicine, Muğla, Turkey

${ }^{2}$ Department of General Surgery, Muğla Sıtkı Koçman University School of Medicine, Muğla, Turkey

\section{Address for Correspondence} Yelda Dere

e-mail:yeldamorgul@gmail.com

Received:22.01.2015

Accepted: 28.02.2015

Available Online Date: 14.07.2015

@) Copyright 2017

by Turkish Surgical Association

Available online at

www.turkjsurg.com
Ossifying fibromyxoid tumor (OFMT), a rare soft tissue tumor, is generally located in the extremities with a distinct morphology characterized by bland, small cells lying in a fibromyxoid stroma and a peripheral rim of the lamellar bone. These tumors mostly express Leu-7, neuron specific enolase in addition to S-100 and vimentin. Some tumors may have malignant cytological features with aggressive behavior but even in classical morphology, recurrence or metastasis can be detected. Thus, the outcome of the tumor remains a mystery and depends on the different results detected during the follow up. Herein, we report a case of OFMT regarding this entity in the differential diagnosis of subcutaneous masses.

Keywords: Ossifying fibromyxoid tumor, trunk, subcutaneous mass, soft tissue

\section{INTRODUCTION}

Ossifying fibromyxoid tumor (OFMT) is a rare soft tissue neoplasm first described by Enzinger in 1989 with uncertain differentiation (1). It is usually a well-defined, small, subcutaneous mass located in the extremities and is slightly more common in men (2). The tumor is characterized by small, round to ovoid cells forming cords and trabeculae in a fibromyxoid matrix. One of the main characteristics of this lesion is the partial rim of metaplastic woven bone surrounding the tumor (3). Despite the classical form, many cytological features such as high mitotic activity and increased cellularity associated with aggressive behavior were described in the literature (4). Herein, we report a case of OFMT, which is subcutaneously located in the trunk and is to be kept in the mind of clinicians and pathologists because of the rarity.

\section{CASE PRESENTATION}

A 43-year-old female patient presented with a palpable mass in the trunk. On physical examination, a small, firm, $2-\mathrm{cm}$ sized mass was revealed over the $5^{\text {th }}$ rib near the epigastric region. There were no abnormalities in the laboratory tests and the tumor was excised with a written consent form taken from the patient.

The specimen was a nodular, gray-white solid mass with fibrotic and lipomatous areas. Gritty areas were detected and the cut surface showed a well-defined, tan-white 1.8-cm sized lesion. Once the tumor was decalcified, two cut surfaces were processed for microscopic examination. In the hematoxylin eosin stained microscopic slides, a small, nodular, and lobulated mass with small ovoid cells surrounded by a fibrous capsule was detected (Figure 1). The tumor was moderately cellular and generally the tumoral cells were scattered in a myxoid stroma. The cells of the tumor were generally round shaped with bland cytological features. However, some cells had fusiform shaped nuclei with inconspicuous nucleoli (Figure 2). The nuclei of the tumoral cells were pale with inconspicious nucleoli. The cytoplasms were clear and scant with an eosinophilic appearance. No granulomas or giant cells and lipoblasts were detected. The mitotic rate was measured as $<1 / 10 \mathrm{HPF}$. The general view of the fibromyxoid matrix was moderately cellular admixed with fibrotic and myxoid areas; however, the matrix was confusing in some foci, showing high vasculature. Perivascular hyalinization was detected in most of the stroma. The stroma was positively stained with PAS.

Many different slides were prepared from different blocks and in only one slide, a partial rim of metaplastic lamellar bone surrounding the tumor was detected (Figure 3). In the immunohistochemical study, vascular structures were positive for CD34 and CD31 but the tumoral cells were negative. However, the tumoral cells showed diffuse positivity of S-100, vimentin, and GFAP, which form the characteristic immune profile of the lesion (Figure 4). The main differential diagnosis was chondroid syringoma, which is also known as mixed tumor. But no ductal epithelial component was detected. Moreover, extraskeletal myxoid chondrosarcoma was considered in the differential diagnosis; however, due to the absence of a cell population with vacuolated cytoplasm and chon- 


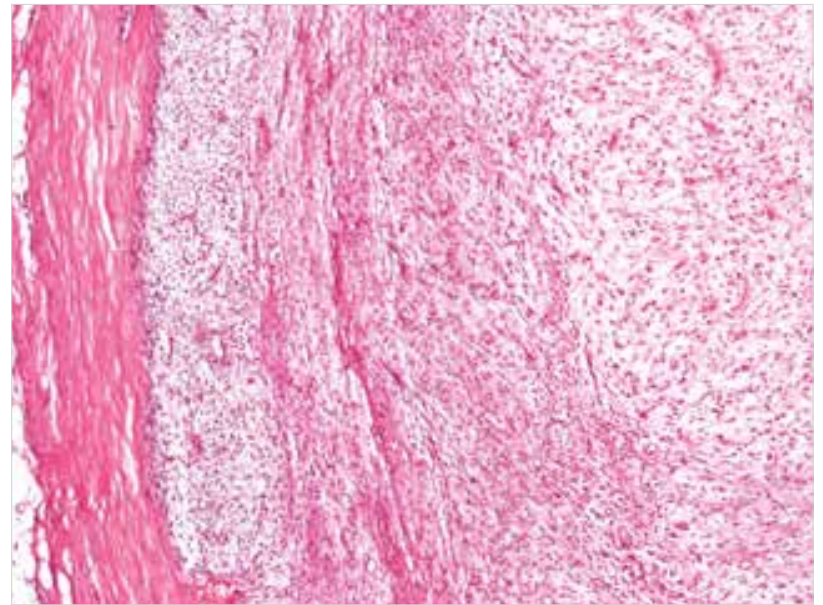

Figure 1. A small, nodular mass with small ovoid cells scattered in a fibromyxoid matrix, $\mathrm{HE}, \times 100$

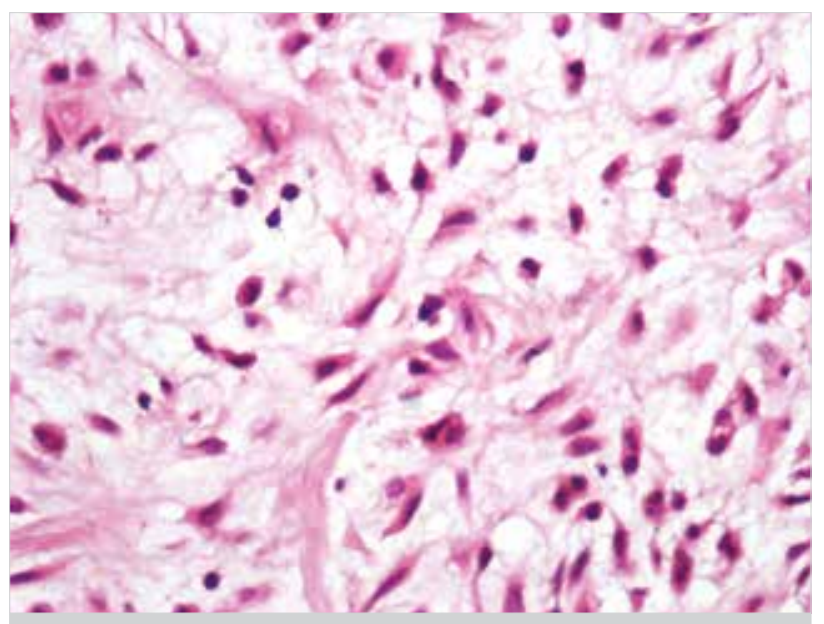

Figure 2. Nests or cords of uniform cells with bland cytological features and inconspicuous nucleoli, $\mathrm{HE}, \times 400$

dromyxoid matrix, this entity was excluded. With these uniform cells, which are positive for vimentin and S-100 in a fibromyxoid stroma in addition to the peripheral rim of the metaplastic bone, the case was diagnosed as OFMT.

The treatment procedure was local excision with intact surgical margins and no additional therapy was provided. The patient was under follow up for 9 months and is disease free.

\section{DISCUSSION}

Ossifying fibromyxoid tumor, firstly described by Enzinger as associated with uncertain differentiation, is usually a small, nodular mass located in the subcutaneous tissue of the extremities (5). Ossifying fibromyxoid tumor is generally observed in adult men with a mean age of 50 years (3). Most cases arise in the lower extremities but different localizations such as head and neck and retroperitoneum were reported $(1,6)$. Despite the classical form of small subcutaneous nodules, OFMTs can reach larger sizes or invade deep soft tissue parts including the bone (7).

The most common presentation is a palpable, well-defined, slowly growing mass; however, many aggressive forms such as those that metastasize to the lungs or those invading the spine were reported in the literature $(8,9)$.

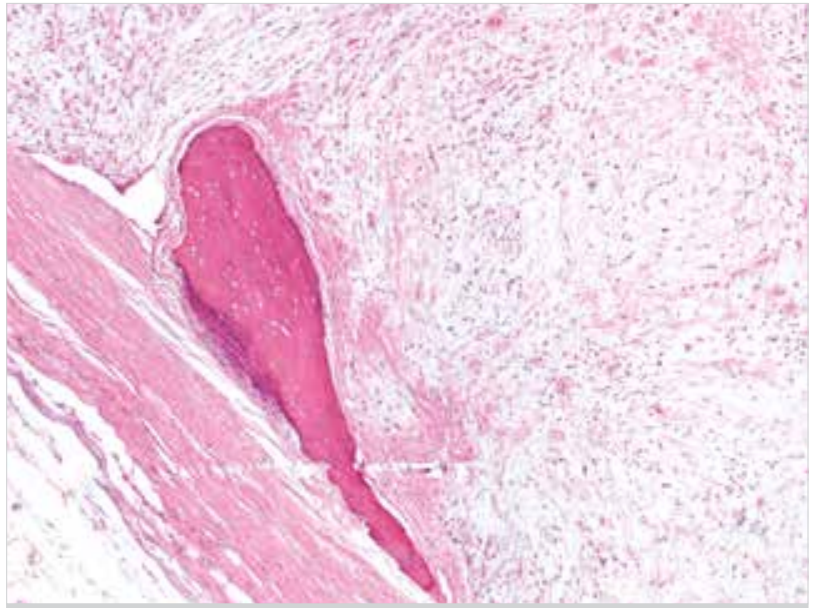

Figure 3. Partial rim of lamellar bone surrounding the tumor, $\mathrm{HE}, \times 200$

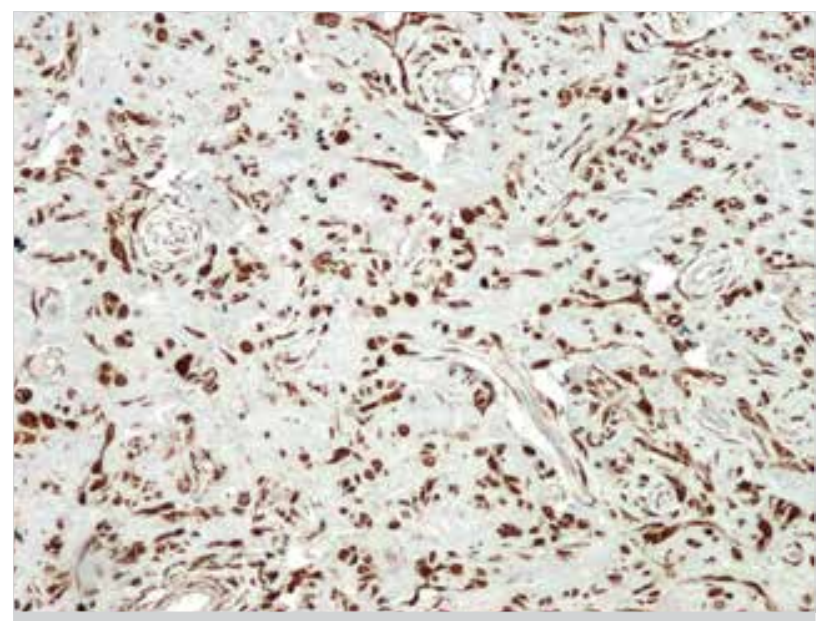

Figure 4. S-100 positivity, DAB, $\times 200$

The tumor comprises small, ovoid cells forming cords, nests, or trabeculae in a fibrous or fibromyxoid stroma. In high power examination, cytologically bland round cells with scattered fusiform shaped nuclei can be observed in a highly vascularized stroma showing perivascular hyalinization $(3,10)$. The stroma shows PAS positivity and a peripheral rim of lamellar bone, which partially surrounds the tumor, can be detected in about $80 \%$ of cases (3). We detected the partial rim of the bone in only one block. Immunohistochemically, OFMTs show a positivity of S-100, vimentin, Leu-7, neuron specific enolase (NSE), and glial fibrillar acidic protein (GFAP) (3). Our case was diffusely positive with S-100, vimentin, and GFAP but the lesional cells were negative for CD34 and CD31. Leu-7 and NSE were not performed due to technical reasons in our laboratory.

The main differential diagnosis is chondroid syringoma, which is also known as a benign mixed tumor of the skin, and comprises of bland tumor cell nodules surrounded by a hyaline myxoid stroma commonly admixed with calcifications as well as ossifications. Ductal/epithelial component arising due to immunoreactivity with cytokeratins can help differentiate these lesions. Myxoma of the nerve sheath is another entity considered in the differential diagnosis; however, no peripheral metaplastic bone formation is seen in this tumor. Extraosseous osteosarcomas are large masses located in deep soft 
tissue parts with highly atypical, pleomorphic cells. Malignant peripheral nerve sheath tumor is a more aggressive tumor generally located in deep counterparts of the soft tissue. Extraskeletal myxoid chondrosarcoma, a malignant soft tissue tumor must also be excluded by detecting tumor cells with more vacuolated cytoplasm and chondromyxoid stroma (4).

The major prognostic features were cellularity, mitotic rate, and nuclear grade in a 3 step classification by Folpe and Weiss (4) grouping OFMT in a) typical form with low cellularity, mitotic rate $<2 / 50 \mathrm{HPF}$, and low nuclear grade; $b$ ) malignant form with high cellularity and nuclear grade, mitotic rate $>2 / 50$ HPF; and c) atypical with intermediate grade between a and b. This classification is important because of the high risk of recurrence and metastasis in malignant OFMTs. In the atypical forms, the rate of local recurrence was stated as $13 \%$ in the study by Folpe et al. (4) and was reported to recur even after 11 years. In the same study, the metastasis was found as $60 \%$ of malignant OFMTs whereas $4 \%$ and $6 \%$ of typical and atypical OFMTs respectively (4). According to this classification, our case can be counted as an typical form of OFMT. In typical OFMTs, complete excision with intact surgical margins is accepted to be optimal but long term follow up of the case is needed because of the potential of different biological behavior $(8,9)$.

The outcome of this tumor remains controversial and depends on the presence of tumors having the same morphology but showing different biological behavior. For example, Yoshida et al. reported a case with aggressive behavior, which caused death of the patient lacking malignant features (9). Binesh et al. (8) described a case showing the classical morphological features of a typical OFMT but metastasized to the lungs. Because of the reports describing tumors with a typical morphological appearance and clinically malignant outcomes, patients should be under close follow-up for recurrence or aggressive behavior.

\section{CONCLUSION}

Ossifying fibromyxoid tumors are rare tumors usually associated with benign behavior but the rarity of the lesion may lead the pathologists to misdiagnose. In our opinion, OFMT deserves to be remembered in the differential diagnosis of subcutaneous masses with these unique features.

Informed Consent: Written informed consent was obtained from patient who participated in this case.
Peer-review: Externally peer-reviewed.

Author Contributions: Concept - Y.D., Ö.D.; Design - Y.D., S.Y.Ç.; Supervision - Ö.D., Ö.I.Ç.; Funding - Y.D.; Materials - Y.D., Ö.D.; Data Collection and/or Processing - S.Y.Ç., Ö.D.; Analysis and/or Interpretation - Y.D., Ö.I.Ç., S.Y.Ç., Ö.D.; Literature Review - Y.D., Ö.I.Ç.; Writer - Y.D., Ö.D.; Critical Review - Ö.I.Ç., S.Y.Ç.; Other - Y.D.

Acknowledgements: Special thanks to Mine Tunakan Öztop and Murat Ermete because of their contribution and application of immunohistochemistry.

Conflict of Interest: No conflict of interest was declared by the authors.

Financial Disclosure: The authors declared that this study has received no financial support.

\section{REFERENCES}

1. Enzinger FM, Weiss SW, Liang CY. Ossifying fibromyxoid tumor of soft parts: A clinicopathological analysis of 59 cases. Am J Surg Pathol 1989; 13: 817-827. [CrossRef]

2. Schaffler G, Raith J, Ranner G, Weybora W, Jeserschek R. Radiographic appearance of an ossifying fibromyxoid tumor of soft parts. Skeletal Radiol 1997; 26: 615-618. [CrossRef]

3. Rubin BP, Stenman G. Tumours of uncertain differentiation. In: Fletcher CDM, Unni KK, Mertens F, editors. Pathology and genetics of tumours of soft tissue and bone. World health organization classification of tumours. Lyon, France: IARC Press; 2002. p. 196-197.

4. Folpe AL, Weiss SW. Ossifying fibromyxoid tumor of soft parts: a clinicopathological study of 70 cases with emphasis on atypical and malignant variants. Am J Surg Pathol 2003; 27: 421-431. [CrossRef]

5. Weiss SW, Goldblum JR, Folpe AL. Miscellaneous tumors of intermediate malignancy. In: Weiss SW, Goldblum JR, editors. Enzinger and Weiss's soft tissue tumors. 5th ed. St. Louis, Mosby; 2008. p. 1093-1160.

6. Shettya SD, Saliba RJ, Naira SB, Mathada N, Theakera J. Ossifying fibromyxoid tumor of the sphenoid sinus. J Laryngol Otol 2010; 124: 437-440. [CrossRef]

7. Cha J H, Kwon J W, Cho E Y, Lee CS, Yoon Y C, Choi SH. Ossifying fibromyxoid tumor invading the spine: a case report and review of the literature. Skeletal Radiol 2008; 37: 1137-1140. [CrossRef]

8. Binesh F, Akhavan A, Navabii H. Ossifying fibromyxoid tumour: a rare soft tissue tumour of intermediate malignancy. BMJ Case Reports 2011; 2011: bcr0820103263.

9. Yoshida H, Minamizaki T, Yumoto T, Furuse $K$, Nakadera T. Ossifying fibromyxoid tumor of soft parts. Acta Pathol Jpn 1991; 4: 480-486. [CrossRef]

10. Çallı AO, Doğan M, Öztop MT, Doğruluk T, Yörükoğlu K. Ossifiyen fibromiksoid tümör: Olgu sunumu. Erciyes Med J 2006; 28: 152-154. 